\title{
Sid New Disease Reports \\ First report of Botrytis porri causing Botrytis leaf blight on leek in Japan
}

T. Misawa ${ }^{1 *}$, R. Ueno ${ }^{2}$, D. Kurose ${ }^{3}$ and K.S. Nakahara ${ }^{4}$

${ }^{1}$ Hokkaido Research Organization, Sapporo, Hokkaido 060-0819, Japan ; ${ }^{2}$ Ornamental Plants and Vegetables Research Center, Hokkaido Research Organization, Takikawa, Hokkaido 073-0026, Japan ; ${ }^{3}$ CABI Europe-UK, Bakeham Lane, Egham, Surrey TW20 9TY, UK ; ${ }^{4}$ Research Faculty of Agriculture, Hokkaido University, Sapporo, Hokkaido 060-8589, Japan

*E-mail: misawa-tomoo@hro.or.jp

Received: 23 Jan 2020. Published: 30 Mar 2020. Keywords: Allium ampeloprasum, fungal plant disease, Hokkaido

Leek (Allium ampeloprasum var. porrum) is a biennial vegetable species belonging to the family Liliaceae. In May 2011 and 2012, leaf spots and leaf blight on leek seedlings were observed in a greenhouse in Hokkaido, Japan. Leaf spot symptoms appeared as pale brown fusiform lesions on the leaves, c. 1-15 mm in length (Fig. 1). Severely damaged leaves showed blight symptoms (Fig. 2). Approximately $80 \%$ of the seedlings in the greenhouse were affected by the disease in both years.

Two fungal isolates (isolate LB1 in 2011 and isolate LBS1 in 2012) were obtained from the leaf lesions. Conidiophores of the two isolates grown on sterilised Chinese chive leaves (Misawa \& Takeuchi, 2015) were erect, with septa, pale to mid brown, branched at the apex, with enlarged apical cells bearing clusters of conidia. The length and width of conidiophores of isolates LB1 and LBS1 were 198-515 $\times$ 9.7-16.7 $\mu \mathrm{m}$ and 255-609 $\times$ 7.8-15.0 $\mu \mathrm{m}$, respectively (Fig. 3). Conidia were not in chains, and they were colourless to pale brown, unicellular, smooth, and ovoid to ellipsoid. Conidial size of isolate LB1 was 11.5-22.7 × 7.1-13.9 $\mu \mathrm{m}$ (mean $17.3 \times$ $10.4 \mu \mathrm{m}$ ), with a length to breadth (L/B) ratio of 1.05-2.21 (mean 1.67) (Fig. 4), whereas that of isolate LBS1 was 10.4-24.0 × 8.4-14.2 $\mu$ m (mean $17.5 \times 11.1 \mu \mathrm{m}$ ), with an L/B ratio of 1.08-2.28 (mean 1.57). Sclerotia of the two isolates were pale brown in colour and c. 1-2 mm in size. The morphological characteristics of the two isolates were similar to those of Botrytis porri as described by Ellis (1971). For further confirmation, nuclear protein-coding genes (G3PDH, HSP60 and RPB2) were sequenced (Staats et al., 2005). The sequences of three genes of isolates LB1 and LBS1 (GenBank Accession Nos. LC511171-511176) were identical. These sequences showed $99.7-100 \%$ identity with those of the type strain (strain MUCL3234) of B. porri (AJ705032, AJ716093 and AJ745704). Based on both morphology and sequence similarity, the two leek isolates were identified as B. porri.

Pathogenicity tests were performed using leek (cv. Pot-au-feu) seedlings

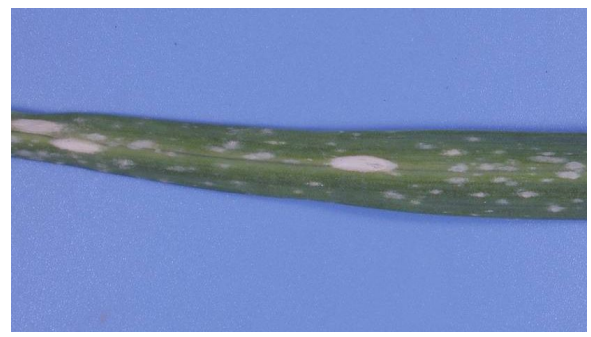

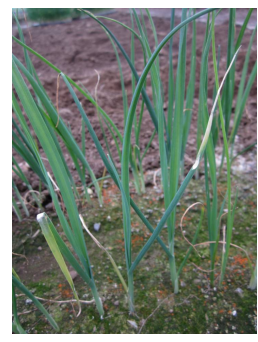

Figure 2 grown in plastic pots $(26.5 \mathrm{~cm}$ length $\times 14.5 \mathrm{~cm}$ width $\times 12.0 \mathrm{~cm}$ depth $)$ for 2.5 months, ten plants per pot. One pot was used for each inoculation test. Two leaves of each plant were wounded with a sterilised needle and the plants were sprayed with either conidial suspension $\left(3.0 \times 10^{5}\right.$ spores $\left./ \mathrm{ml}\right)$ or sterilised distilled water (control). The inoculated plants were covered with plastic bags and placed in a growth chamber in controlled conditions at $15^{\circ} \mathrm{C}$ with a $16 / 8 \mathrm{hr}$ light/dark cycle. The bags were removed three days after inoculation (dai). Inoculated plants developed leaf spot symptoms three dai, and the spots grew to $5-15 \mathrm{~mm}$ in length; some leaves showed blight symptoms seven dai (Fig. 5). All inoculated leaves showed these symptoms, and the symptoms were similar to those of naturally diseased plants. Control plants remained healthy. The causal fungus was re-isolated from inoculated leaves, thereby fulfilling Koch's postulates. This is the first report of B. porri causing Botrytis leaf blight on leek in Japan. The two isolates were deposited in the NARO Genebank, National Agriculture and Food Research Organization, Japan as MAFF 245625-245626.

\section{References}

1. Ellis MB, 1971. Dematiaceous Hyphomycetes. Kew, UK: Commonwealth Mycological Institute.

2. Misawa T, Takeuchi M, 2015. Species composition of Botrytis leaf blight pathogens of Chinese chives and their seasonal and annual changes in Hokkaido, Japan. Journal of General Plant Pathology 81, 218-225. http://dx.doi.org/10.1007/s10327-015-0588-9

3. Staats M, van Baarlen P, van Kan JAL, 2005. Molecular phylogeny of the plant pathogenic genus Botrytis and the evolution of host specificity.Molecular Biology and Evolution 22, 333-346. http://dx.doi.org/10.1093/molbev/msi020

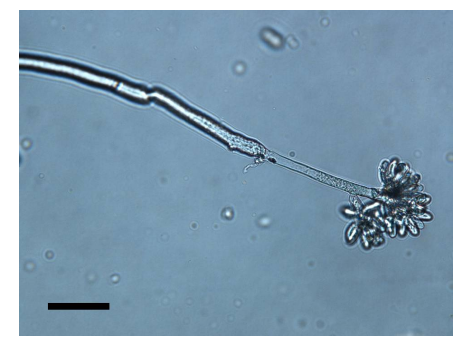

Figure 3
Figure 1

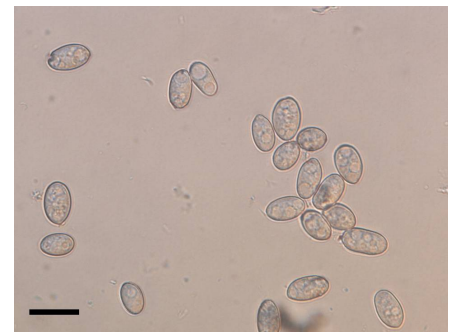

Figure 4

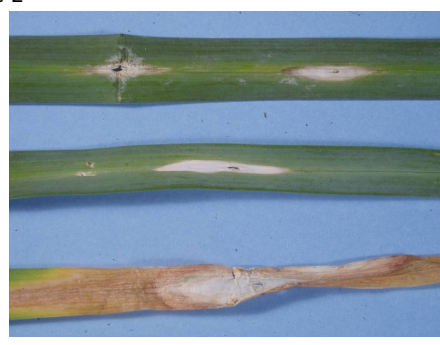

Figure 5

To cite this report: Misawa T, Ueno R, Kurose D, Nakahara KS, 2020. First report of Botrytis porri causing Botrytis leaf blight on leek in Japan. New Disease Reports 41, 19. http://dx.doi.org/10.5197/j.2044-0588.2020.041.019

(c) 2020 The Authors

This report was published on-line at www.ndrs.org.uk where high quality versions of the figures can be found. 